\title{
Reaction of Chilli Genotypes against Chilli veinal mottle virus (ChiVMV) under Glass House Condition
}

\author{
Nandappa Chorgasti*, R. Ganesha Naik and H.M. Renuka \\ Department of Plant Pathology, College of Agriculture, \\ University of Agricultural and Horticultural Sciences, Shivamogga-577225, India \\ *Corresponding author
}

\begin{abstract}
A B S T R A C T
Chilli veinal mottle virus (ChiVMV) is an aphid-borne major destructive

\section{Keywords}

Screening, DACELISA, Chilli veinal mottle virus, Capsicum annuum, Inoculation

Article Info

Accepted:

20 June 2020

Available Online:

10 July 2020 virus affecting chilli crop. To identify sources of resistance against ChiVMV is essential. In this study, fifty chilli genotypes were screened for ChiVMV resistance through mechanical inoculation in an insect-proof glass house. Totally 50 Chilli genotypes were screened against ChiVMV, through symptomatology and serology (DAC-ELISA) under glasshouse conditions showed that five genotypes viz., BKS-02, BKS-19, BKS-25, BKS-36 and BKS-42, showed highly resistant (HR) reaction. Ten genotypes viz., BKS-05, BKS-09, BKS-16, BKS-36, BKS-39, BKS-40, BKS-41, BKS-43, BKS-45, and BKS-50 showed resistant (R) reaction. Six genotypes viz., BKS-03, BKS-06, BKS-14, BKS-28, BKS-33, and BKS-38, showed moderately resistant (MR) reaction and remaining were shown a susceptible reaction.
\end{abstract}

\section{Introduction}

Chilli (Capsicum annuum L.) is one of the most important vegetable and spice crop belonging to the family Solanaceae and widely grown in India. It is commercially grown in tropical and subtropical regions of the world. It requires a long and warm climate for its growth and development. Chilli has been widely distributed across the world and prone to many biotic and abiotic stresses.
Biotic agents like fungi (Fruit rot/Dieback, Damping off), bacteria (Ralstonia wilt), viruses (Chilli veinal mottle virus, Chilli leaf curl virus and Cucumber mosaic virus) and nematodes (Root-knot nematode). Among these, viral diseases are known to be a major threat to the production of chilli resulting in low yields and poor fruit quality (Alanso et al., 1989 and Fujisawa et al., 1986). Among the viral diseases, after Chilli leaf curl virus, Chilli veinal mottle virus (ChiVMV) is a most 
destructive virus affecting the chilli cultivation. It is the member of potyvirus genus in the family Potyviridae. Potyvirus is the largest of the 34 plant virus groups and families currently recognised (VanRegenmortel et al., 2008), ChiVMV is transmitted by several species of aphids viz., green peach aphid (Myzus persicae) cotton melon aphid (Aphis gossypii) cowpea aphid, (Aphis craccivora) in a non-persistent manner (Ward and Shukla., 1992). Continuous breeding effort should also be made to screen and evaluate available chilli germplasm so that breeders could get resistant material to incorporate resistance gene in highly susceptible cultivars as well for farmers to improve chilli yield (Moury et al., 2005 and Shah et al., 2011). The use of conventional phytosanitary practices is often inefficient against these potyviruses because they spread rapidly in the field through non-persistent manner by aphids. Thus, resistant cultivars remain the most economical and reliable method of control. Hence, an effort was made to screen the available chilli germplasms against ChiVMV through most reliable, authentic and convenient approach, i.e., serology (DAC-ELISA) under insect proof glasshouse conditions.

\section{Materials and Methods}

Maintenance of virus culture inoculation and ELISA

The ChiVMV culture was maintained on Datura metel plants by mechanical inoculation and renewed every 2 to 3 weeks in an insect proof glass house. To identify sources of resistance against Chilli veinal mottle virus (ChiVMV), different genotypes of chilli were screened in an insect-proof glass house. Totally 50 Chilli genotypes were collected from Horticulture Research and Extension Service, (HRES) Devihosur of Haveri district, University of Horticultural Sciences, Bagalkot, Karnataka, India.
Test plants were raised in portrays of 50 seedlings capacity, and for each set of test seedlings, a tray of susceptible check Byadgi kaddi was included. Screening of germplasm for ChiVMV resistance was done by mechanical inoculation. The infected leaf tissue was ground in a sterilized pre-chilled mortar and pestle in chilled $0.05 \mathrm{M}$ phosphate buffer $\mathrm{pH}$ : 7 with $0.15 \mathrm{M} \beta$-mercaptoethanol, sieved through muslin and then mechanically inoculated at the first true leaf stage. Plants were monitored regularly until the experiment was completed. Leaf samples were taken for ELISA and the final phenotypic evaluation was performed six weeks after inoculation. Direct antigen coated ELISA (DAC-ELISA) was performed following the method of Hobbs et al., (1981) using ChiVMV specific antibodies (Bioreba AG, Reinach, Switzerland). A sample was considered positive for infection when the ELISA absorbance value was greater than the average absorbance of healthy un-inoculated control tissue. Based on the per cent incidence and OD (Optical density) values detected the presence of Chilli veinal mottle virus (ChiVMV) in all 50 chilli genotypes through DAC-ELISA. The chilli germplasm were categorized as, $0 \%$ - Immune, 1-10 \%Highly resistant, 11-25\%- Resistant, 26-40 \%- Moderately resistant, 41-60 \%Susceptible and $>60 \%$ - Highly susceptible (Reddy et al., 2001).

The following diseased rating scale was adopted (Krishna Reddy et al., 2001) (Table $1)$.

\section{Results and Discussion}

Results on reaction of chilli genotypes against Chilli Veinal Mottle Virus (ChiVMV) during 2017-2018 are presented in Table 2. The expression of ChiVMV symptoms including, chlorotic local lesions, mosaic, mottling, vein banding and leaf distortion. The typical dark green vein banding was observed in 
susceptible plants. To assess the resistance of chilli genotypes against ChiVMV a total of 50 genotypes were screened under the insectproof glasshouse condition. The per cent disease incidence was recorded as soon as symptom appeared on each genotype up to six weeks and each genotype was confirmed through DAC-ELISA and the genotypes were categorized into immune (I), highly resistant (HR), resistant (R), moderately resistant (MR), susceptible (S) and highly susceptible (HS).

Accordingly five genotypes viz., BKS-02, BKS-19, BKS-25, BKS-32 and BKS-42 were found highly resistant and exhibited low incidence of disease and lower absorbance values in ELISA, ten genotypes viz., BKS05,BKS-09, BKS-16, BKS-36, BKS-39, BKS-40, BKS-41, BKS-43, BKS-45 and BKS-50 were resistant and six genotypes viz., BKS-03, BKS-06, BKS-14, BKS-28, BKS-33 and BKS-38 showed moderate resistant reaction.

However, twelve genotypes viz., BKS-04, BKS-07, BKS-08, BKS-10, BKS-15, BKS21, BKS-29, BKS-31, BKS-34, BKS-44, BKS-47 and BKS-49 were found susceptible, while seventeen genotypes viz., BKS-01, BKS-11, BKS-12, BKS-13, BKS-17, BKS18, BKS-20, BKS-22, BKS-23, BKS-24
BKS-26, BKS-27, BKS-30, BKS-35, BKS37, BKS-46 BKS-48 and Byadagi kaddi (Local cultivar) were found highly susceptible reaction and positive reaction to ChiVMV by ELISA.

Krishna Reddy et al., (2004) screened 25 chilli pepper genotypes against the Chilli veinal mottle virus (ChiVMV) isolates and classified them into five groups based on the disease intensity and ELISA OD values and reported that three lines found to be immune to all the isolates, 10 lines were reacted immune to the resistant reaction, two lines showed resistant to the susceptible reaction and the remaining 10 lines were highly susceptible to different isolates of Chilli veinal mottle virus (ChiVMV). Hidayat et al., (2012) in Indonesia reported different chilli varieties with disease reaction i.e. highly resistant, resistant, moderately susceptible, Susceptible and highly susceptible. Naresh et al., (2016) screened 50 Capsicum genotypes against Chilli veinal mottle virus (ChiVMV) and reported 17 genotypes were found immune, one was highly resistant, whereas five genotypes were resistant and two genotypes were moderately resistant against Chilli veinal mottle virus (ChiVMV). These results are in accordance with the results of the present investigation.

Table.1 Disease Incidence Scale for Chilli veinal mottle virus (ChiVMV)

\begin{tabular}{|l|c|c|}
\hline Reaction & $\%$ incidence & OD values \\
\hline Immune & 0 & $<0.109$ \\
\hline Highly resistant & $1-10$ & $0.109-0.300$ \\
\hline Resistant & $11-25$ & $0.301-0.600$ \\
\hline Moderately resistant & $26-40$ & $0.601-0.800$ \\
\hline Susceptible & $41-60$ & $0.801-1.000$ \\
\hline Highly susceptible & $>60$ & $>1.000$ \\
\hline
\end{tabular}


Table.2 Reaction of chilli genotypes against ChiVMV under glasshouse condition by mechanical inoculation

\begin{tabular}{|c|c|c|c|c|c|}
\hline Sl. No. & Genotypes & $\begin{array}{c}\text { Per cent } \\
\text { incidence }(\%)\end{array}$ & OD Value & Type of symptoms & $\begin{array}{l}\text { Disease } \\
\text { reaction }\end{array}$ \\
\hline 1 & BKS-01 & 90.00 & 1.5630 & Ld, Vb, MMo & HS \\
\hline 2 & BKS-02 & 10.00 & 0.2331 & M, MMo & HR \\
\hline 3 & BKS-03 & 30.00 & 0.6706 & $\mathrm{Vb}, \mathrm{Ld}$ & MR \\
\hline 4 & BKS-04 & 50.00 & 0.8020 & $\mathrm{Vb}, \mathrm{Ld}$ & $\mathrm{S}$ \\
\hline 5 & BKS-05 & 20.00 & 0.5172 & M, Ivc & $\mathrm{R}$ \\
\hline 6 & BKS-06 & 30.00 & 0.6940 & M, MMo & MR \\
\hline 7 & BKS-07 & 50.00 & 0.9722 & $\mathrm{Vb}, \mathrm{Ld}$ & $\mathrm{S}$ \\
\hline 8 & BKS-08 & 50.00 & 0.9026 & $\mathrm{Vb}, \mathrm{Ld}$ & $\mathrm{S}$ \\
\hline 9 & BKS-09 & 20.00 & 0.4206 & M, Ivc & $\mathrm{R}$ \\
\hline 10 & BKS-10 & 50.00 & 0.8760 & $\mathrm{Vb}, \mathrm{Ld}$ & $\mathrm{S}$ \\
\hline 11 & BKS-11 & 70.00 & 1.0151 & MMo, Ld, Vb & HS \\
\hline 12 & BKS-12 & 80.00 & 1.0303 & $\mathrm{SM}, \mathrm{Vb}, \mathrm{Ld}$ & HS \\
\hline 13 & BKS-13 & 90.00 & 1.0011 & SMMo, Vb, Ivc & HS \\
\hline 14 & BKS-14 & 30.00 & 0.6196 & $\mathrm{M}, \mathrm{Ivc}$ & MR \\
\hline 15 & BKS-15 & 50.00 & 0.9810 & SMMo, Vb & $\mathrm{S}$ \\
\hline 16 & BKS-16 & 20.00 & 0.5309 & $\mathrm{M}, \mathrm{Vb}$ & $\mathrm{R}$ \\
\hline 17 & BKS-17 & 70.00 & 1.0020 & SMMo, Vb, Ld & HS \\
\hline 18 & BKS-18 & 80.00 & 1.0050 & $\mathrm{SM}, \mathrm{Vb}, \mathrm{Ld}$ & HS \\
\hline 19 & BKS-19 & 10.00 & 0.2393 & $\mathrm{Vb}$ & HR \\
\hline 20 & BKS-20 & 60.00 & 1.0010 & $\mathrm{SM}, \mathrm{Vb}, \mathrm{Ld}$ & HS \\
\hline 21 & BKS-21 & 50.00 & 0.8240 & $\mathrm{M}, \mathrm{Vb}$ & $\mathrm{S}$ \\
\hline 22 & BKS-22 & 80.00 & 1.0000 & $\mathrm{SM}, \mathrm{Vb}, \mathrm{Ld}$ & HS \\
\hline 23 & BKS-23 & 90.00 & 1.0010 & SMMo, Vb, Ivc & HS \\
\hline 24 & BKS-24 & 80.00 & 0.9990 & $\mathrm{SM}, \mathrm{Vb}, \mathrm{Ld}$ & HS \\
\hline 25 & BKS-25 & 10.00 & 0.2376 & SMMo & HR \\
\hline 26 & BKS-26 & 90.00 & 1.0200 & SMMo, Vb, Ivc & HS \\
\hline 27 & BKS-27 & 90.00 & 1.1100 & SMMo, Vb, Ivc & HS \\
\hline 28 & BKS-28 & 40.00 & 0.7024 & MMo & MR \\
\hline 29 & BKS-29 & 60.00 & 0.8224 & $\mathrm{Vb}, \mathrm{Ld}$ & $\mathrm{S}$ \\
\hline 30 & BKS-30 & 100.00 & 1.1223 & MMo, Ld, Cp, Vb & HS \\
\hline 31 & BKS-31 & 60.00 & 0.8252 & $\mathrm{Vb}, \mathrm{Ld}$ & $\mathrm{S}$ \\
\hline 32 & BKS-32 & 10.00 & 0.2559 & $\mathrm{Vb}, \mathrm{SMMo}$ & HR \\
\hline 33 & BKS-33 & 40.00 & 0.6808 & $\mathrm{M}, \mathrm{Vb}, \mathrm{Ld}$ & MR \\
\hline 34 & BKS-34 & 50.00 & 0.9010 & SMMo, Vb & $\mathrm{S}$ \\
\hline 35 & BKS-35 & 70.00 & 1.0010 & SMMo, Vb, Ld & HS \\
\hline 36 & BKS-36 & 20.00 & 0.3865 & $\mathrm{M}, \mathrm{Vb}$ & $\mathrm{R}$ \\
\hline 37 & BKS-37 & 70.00 & 1.1001 & SMMo, Vb & HS \\
\hline 38 & BKS-38 & 30.00 & 0.6254 & MMo & MR \\
\hline 39 & BKS-39 & 20.00 & 0.3862 & $\mathrm{M}, \mathrm{Vb}$ & $\mathrm{R}$ \\
\hline 40 & BKS-40 & 20.00 & 0.4345 & $\mathrm{M}, \mathrm{Vb}$ & $\mathrm{R}$ \\
\hline 41 & BKS-41 & 20.00 & 0.3606 & MMo & $\mathrm{R}$ \\
\hline 42 & BKS-42 & 10.00 & 0.2407 & Vb, SMMo & HR \\
\hline 43 & BKS-43 & 20.00 & 0.3394 & SMMo, Vb & $\mathrm{R}$ \\
\hline 44 & BKS-44 & 60.00 & 0.8214 & $\mathrm{SM}, \mathrm{Vb}, \mathrm{Ld}$ & $\mathrm{S}$ \\
\hline 45 & BKS-45 & 20.00 & 0.3414 & SMMo, Vb, Ivc & $\mathrm{R}$ \\
\hline 46 & BKS-46 & 80.00 & 1.1020 & SMMo, Vb, Ld & HS \\
\hline 47 & BKS-47 & 70.00 & 0.9112 & $\mathrm{SM}, \mathrm{Vb}, \mathrm{Ld}$ & $\mathrm{S}$ \\
\hline 48 & BKS-48 & 80.00 & 1.1341 & SMMo, Vb, Ld & HS \\
\hline 49 & BKS-49 & 50.00 & 0.8154 & SMMo, Vb, Ld & $\mathrm{S}$ \\
\hline 50 & BKS-50 & 20.00 & 0.4002 & SMMo, Vb & $\mathrm{R}$ \\
\hline 51 & $\begin{array}{l}\text { Byadagi kaddi } \\
\text { (Local cultivar) }\end{array}$ & 100.00 & 1.1324 & M, SMMo, Vb, Ld & HS \\
\hline
\end{tabular}


It may be concluded that some resistant genotypes were identified which can be used in the breeding programme for varietal improvement against the virus. The present study showed that, five genotypes showed highly resistant, ten were resistant, six were moderately resistant, twelve were showed a susceptible reaction and remaining seventeen were showed a highly susceptible reaction to the disease.

\section{References}

Alanso, E., Garcia, L. I., Avilla-rincon, M. J., Wicke, B., Serra, M. T. and Diaz-ruiz, J. R., 1989, A tobamovirus causing heavy losses in protected pepper crops in Spain. $J$. Phytopathol., 125: 67-76.

Fujisawa, I., Hanada, T. and Saharan, A., 1986, Virus disease occurring on some vegetable crops in West Malaysia. Japan. Agri. Res. Quarterly, 20 (1): 78-84.

Hidayat, S. H., Opriana, E., Manzila, I. and Sujiprihati, S., 2012, Occurrence of chilli veinal mottle virus (ChiVMV) in Indonesia and response of chilli germplasms to ChiVMV infection. J. ISSAAS., 18(2): 5561.

Hobbs, H. A., Reddy, D. V. R., Rajeswari, R. and Reddy, A. S., 1987, Use of direct coating and protein A coating ELISA procedure for detection of three peanut viruses. Pl. Dis., 71: 747-749.

Krishna reddy, M., Sadashiva, A. T., Madhavi reddy, K., Celia chalam, desphande, A. A. and Jagadish chandra, 2001, Leaf curl and other viruses of Tomato and Pepper. In: final workshop of South Asia Vegetable
Research Network Phase II AVRDC, pp 2833, Bangkok, Thailand.

Krishna reddy, M., Mahadevi reddy, K., Lakshminarayana, R. C. N., Smitha, R. and Jalali, S., 2004, Molecular characterization and genetic variability of Chilli veinal mottle virus and its reaction on chilli pepper genotypes. In: 12th Eucarpia meeting on capsicum and eggplant, Noordwijk, Netherlands.

Moury, B., Palloix, A., Caranta, C., Gognalons, P., Souche, S., Selassie, K. G., and Marchoux, G., 2005, Serological, molecular, and pathotype diversity of pepper veinal mottle virus and chilli veinal mottle virus. Phytopathol., 95(3): 227-232.

Naresh, P., Krishna reddy, M., Hema chandra, R. P. and Mahadevi, R. K., 2016, Screening chilli ( Capsicum spp.) germplasm against cucumber mosaic virus and Chilli veinal mottle virus and inheritance of resistance. European. J. Pl. Pathol., 146: 451-464.

Shah, H., Tahira, Y., Fahim, M., Hameed, S., Munir, I. U. M. and Khanzada, K. A., 2011, Reaction of exotic and indigenous capsicum genotypes against Pakistani isolates of Chili veinal mottle virus. Pakistan J. Bot., 43 (3): 1707-1711.

Van-regenmortel, M. H. V., Fauquet, C. M., Bishop, D. H. L., Carstens, E. B., Estes, M. K., Lemon, S. M., Maniloff, J., Mayo, M. A., Mcgeoch, D. J., Pringle, C. R. and Wickner, R. B., 2008, Virus Taxonomy: $7^{\text {th }}$ Report of the International Committee on Taxonomy of Viruses.

Ward, C. W. and Shukla, D. D., 1992, Taxonomy of potyviruses: current problems and some solutions. Intervirol., 32: 269-296.

\section{How to cite this article:}

Nandappa Chorgasti, R. Ganesha Naik and Renuka, H.M. 2020. Reaction of Chilli Genotypes against Chilli veinal mottle virus (ChiVMV) under Glass House Condition. Int.J.Curr.Microbiol.App.Sci. 9(07): 2401-2405. doi: https://doi.org/10.20546/ijcmas.2020.907.280 